\section{THE INDIAN MEDICAL SERVICE AND THE PROPOSED MEMORIAL TO THE}

\section{ARMY MEDICAL OFFICERS.}

To the Editor of THE LANCET.

SIR,-My fellow medical officers of the Indian Army will hardly credit me when I inform them that, by the decision of the Committee at Whitehall, the proposed memorial to the memory of the army medical officers who fell in the campaigns in Afghanistan and Zululand is to be confined to the officers of the Army Medical Department, and has not any reference to the memory of the officers of the Indian Medical Service; yet such is the case. Now, Sir, as far as I have been able to gather, twelve medical officers lost their lives from wounds received in action or from disease contracted during the campaign whilst serving their country in Afohanistan. Of these six belonged to the Indian Army, whilst the list of invalided and wounded far exceeds that of the Army Medical Department. The Indian Medical Defence Fund has done good service in pointing out how, under the specious guise of amalgamation, the military branch of the Indian Medical Service has been absolutely ruined. It has, however, been reserved for the Comnittee of the proposed memorial to show to the officers of the Indian Service that, notwithstanding this amalgamation of the two services under one surgeon-general-always be it remarked belonging to the Army Medical Department-a memorial which should have been common to all medical officers who fell in the campaign in Afghanistan has been reserved exclusively for those of the Army Medical Department. I would suggest, through the medium of your columns, that a committee be formed in India for erecting likewise a memorial to those surgeons of the Indian Army who lost their lives whilst serving their country in Afohanistan.

I am, Sir, your obedient servant,

ANDREW DuNCAN, M.D., \&c.,

August 13th, 1981. Surgeon late attached to 8th Bengal Cavalry.

* * We regret the ungenerous and narrow-minded decision of the Committee, and trust that the subscribers to the fund will record their protest against it and induce the Committee to reconsider the question, -ED. L.

\section{THE INSANE IN PRIVATE DWELLINGS.}

\section{To the Editor of THE LANCET.}

STr, - The following case bears confirmation of the remarks of Mr. Gramshaw, in to-day's LANCET, upon the advantages to be derived from the treatment of the insane under private care, with domestic and social surroundings differing entirely from those of the lunatic asylum. This modification of medical charge is more especially of service in the earliest stages of mental disorder, when lunacy is impending. Judicious private medical care does then often avert the evil, as was seen in the instance here related.

A lady aged forty years, the mother of a large family, fell into a most abject despondency, fancying that through some fault of her own, before the children were born, they all were doomed to misery, pain, and early deaths. Influenced by these delusions she felt constrained, if she could have got the opportunity, to kill them all, in order to avert the fate she had marked out for them. She went about constantly bemoaning her lot, or sat moody and silent. Under these melancholy conditions it was considered that there was no escape from the imposition of certificates of lunacy. So urgent, however, and strenuous was the objection to this plan on the part of her husband, that the medical man to whom she was taken agreed to incur the legal risk of trying private treatment for a month. The result has been more successful than under the most sanguine view could have been hoped. In less than five weeks the patient had completely lost all her delusions and gloominess, and was restored to her family-it is to be hoped permanently recovered.

Here was an instance of the acute form of melancholia, in which not unfrequently the most appalling catastrophes occur, but which by wise early treatment passed off in, it is true, a very unusually short period.

I remain, Sir, your obedient servant,

London, Aug. 19th, 1881.

M.D.

\section{NOTIFICATION OF INFECTIOUS DISEASE.}

To the Editor of THE LANCET.

SIR,-The Reading Corporation have got inserted in their new Act, just passed, a clause maling it compulsory on any medical man attending a case of infectious disease to at once report it to the medical officer of health. No mention is made of a fee to be paid for the information. It is questionable whether it would not have been more in accordance with the opinion of the profession at large to have thrown this duty on the householder, and not on the medical attendant.

Reading, Aug. 24th, 1881 I am, Sir, your obedient servant,

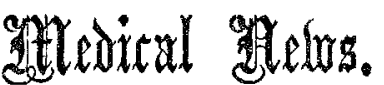

APOTHECARIES' HALL. - The following gentlemen passed their examination in the Science and Practice of Medicine, and received certificates to practise, on Aug. 18th :Grün, Edward Ferdinand, Osborne Villas, Putney. Longman, Arthur, Andover, Hants. Rees, John, Maesteg, South Wales. Webster, George Leonard, Portsdown-road, w.

The following gentlemen also on the same day passed the Primary Professional Examination :Bruce, Robert Marston, St. Thomas's Hospital. Thomas, John Henry, London Hospital. Tread well, Oliver F. N., St. Thomas's Hospital. Walker, Joseph, Liverpool Royal Infirmary.

THE Irish Society of London has given 510 acres for a public park for Londonderry.

ON Sunday, the 14th inst., the new chapel for the Stapleton Lunatic Asylum was sufficiently advanced towards completion to allow of its being used for divine service.

Dr. Fitzgeralid, of the Grey Hospital, King Williamstown, has succeeded in establishing vaccination among the natives, and distributes lymph to all missionaries who apply.-The Colonies and India.

A $\mathrm{T}$ Eastbourne, in the Devonshire-park, is now open an exhibition of sanitary appliances, \&c. Lectures are given in the afternoons and evenings. On Monday Dr. Carpenter addressed the visitors, taking as his subject the question, "Why are Man's Days Shortened?"

Hosprtal NuRses at THE School of CoOKERY.A class will commence on Tuesday, September 6th, of nurses belonging to St. Thomas's Hospital at the National Training School for Cookery, Exhibition-road, South Kensington, to receive instruction in the details of sick-room cookery, which will no doubt much promote the labours of the medical staff, and provide for the patients suitably-prepared food to meet the necessities of the case. This is one of the first classes that has been sent from a hospital for instruction in this most important but much neglected branch of cookery.City Press.

\section{Aftedical Aprointments.}

Intimations for this column must be sent DIRECT to the Office of THE LANCET before 9 o'clock on Thursday Morning, at the latest.

Barton, T. B., A.B., M.D., L.R.C.S.I., L.M., has been appointed Surgeon to the County Donegal Hospital, Lifford, vice $R$. Little, F.R.C.S.I., deceased.

BISDÉE, A. J. M.R.C.S. T.S.A.Lond, has been appointed Medical SDÉE, A. J., M.R.C.S., L.S.A.Lond, has been appointed Medical Officer and Public Vaccinator for the
Axbridge Union, vice Wade, resigned.

Crarkson, J. B., L.R.C.P.Ed., L.R C.S.Ed., late Assistant Medical Officer to the National Line s.s. Spain, has been appointed Medical Officer to the National Line Steamship Company.

CUMING, J., M.D. Q.U.I., F.K.Q.C.P.I., has been reappointed Physician to the Belfast Royal Hospital.

DAY, E. J., F.C.S., M.R.C.S., L.S.A.Lond., Analyst for Dorchester and Bridport Boronghs, and Rural Medical Officer of Health, has been reappointed Medical Officer of Health for the Dorchester Urban Sanitary District.

DutTon, T., M.B., L.R.C.P., \&c., has been appointed Medical Officer and Public Vaccinator to the Manhood District, Westhampnet Union, vice N. E. Cresswell, M.D., M.R.C.S., \&c., resigned.

FAGAN, J., I.K.Q.C.P.I., F.R.C.S.I., has been reappointed Surgeon to the Belfast Royal Hospital. Fenneld, C. J., M.R.C.S., has been appointed Dispenser to the Royal
Hospital, Chelsea. 